Article

\title{
Effects of Varied Shear Correction on the Thermal Vibration of Functionally-Graded Material Shells in an Unsteady Supersonic Flow
}

\author{
Chih Chiang Hong \\ Department of Mechanical Engineering, Hsiuping University of Science and Technology, Taichung 412-80, \\ Taiwan; cchong@mail.hust.edu.tw; Tel.: +886-919-037-599 \\ Academic Editor: Rafic Ajaj \\ Received: 9 January 2017; Accepted: 21 February 2017; Published: 1 March 2017
}

\begin{abstract}
A model is presented for functionally-graded material (FGM), thick, circular cylindrical shells under an unsteady supersonic flow, following first-order shear deformation theory (FSDT) with varied shear correction coefficients. Some interesting vibration results of the dynamics are calculated by using the generalized differential quadrature (GDQ) method. The varied shear correction coefficients are usually functions of FGM total thickness, power law index, and environment temperature. Two parametric effects of the environmental temperature and FGM power law index on the thermal stress and center deflection are also presented. The novelty of the paper is that the maximum flutter value of the center deflection amplitude can be predicted and occurs at a high frequency of applied heat flux for a supersonic air flow.
\end{abstract}

Keywords: supersonic; FGM; varied shear correction coefficient

\section{Introduction}

There are some aero-elastic flutter and vibration research articles of beams, shells, and plates. Samadpour et al. [1] investigated the supersonic flutter of composite beams with shape memory alloys (SMA) under thermal and aerodynamic loads, the aero-thermal flutter characteristics can be enhanced by embedding with SMA fibers in the laminated beam. Liu et al. [2] investigated the effects of supersonic aerodynamic and thermal loads on functionally-graded material (FGM) cylindrical shells, the results of nonlinear dynamics responses are obtained. Li and Narita [3] presented the optimal design in flutter analysis of supersonic flow over doubly-curved shallow laminated shells by using MATLAB code, the optimal fiber orientation angles are obtained. Alijani and Amabili [4] presented the reviewing 2003-2013 papers of vibration shells included the effects of fluid-structure interactions and thermal loads, non-linear vibrations of shells are addressed. Amabili et al. [5] used Donnell's non-linear geometric shallow shell theory to investigate the dynamics and stability for a very thin, circular cylindrical shell within internal water flow, a complex dynamical behavior is obtained. Kiiko [6] studied the vibration of a shallow cylindrical shell in a supersonic gas flow, the well-known formula of "piston" theory is used as a compressive force. There are some recently published research of the subject of the effects of shear deformation theory on the displacements of FGM plates and shells. Yin et al. [7] used higher-order shear deformation theory (HSDT) to investigate the buckling loads and natural eigenvalues of FGM plates, for considering shear deformation effect without requiring any shear correction factors. Bui et al. [8] used the third-order shear deformation theory (TSDT) to investigate the static bending deflections and natural frequencies of FGM plates, also without requiring any shear correction factors. Sun et al. [9] used Donnell's shell theory in the deflection and the lower-order Hamiltonian canonical equations in the fundamental buckling equations to investigate the critical loads and buckling modes of the FGM shells under thermal environment, the mixtures 
of $\mathrm{Si}_{3} \mathrm{~N}_{4} / \mathrm{SUS} 304$ and $\mathrm{Al}_{2} \mathrm{O}_{3} / \mathrm{SUS} 304$ materials are studied. Yin et al. [10] used first-order shear deformation theory (FSDT) to investigate the static bending, buckling, and the free vibration of FGM plates, numerical results with the effects of boundary conditions, gradient index, and geometric shape are presented.

There are some works based on Carrera unified formulation (CUF) for the technical models and analyses in the non-linear displacement fields. Ramos et al. [11] used a unified new trigonometric displacement field expansion under CUF to investigate the static problem of laminated plates under thermal loads, the stress results including the effects of shear deformation are obtained and compared. Mantari et al. [12] used new non-polynomial displacement fields via CUF to investigate static problem of FGM plates, the static bending results with the effects of trigonometric, exponential and hyperbolic displacement fields are presented. There are some technical contents of generalized differential quadrature (GDQ) computation in the composited shells and plates. Hong [13] used the GDQ method to compute the time responses of displacements and stresses for composite magnetostrictive shells under rapid heating without considering the shear deformation effects. Hong [14] also used the GDQ method to investigate the time responses of displacements and stresses for magnetostrictive FGM plates under rapid heating with considering the FSDT effects. Ferreira et al. [15] used the Carrera unified formulation and the GDQ technique to compute the better solutions of static deformations and free vibration for thick isotropic and cross-ply laminated plates. Hong [16] presented the thermal vibrations of Terfenol-D FGM plates including the effects of FSDT model and varied values of modified shear correction factor. Hong [17] studied the thermal vibration of Terfenol-D FGM circular cylindrical shells under rapid heating without considering the effects of shear deformations. The non-linear coefficient term of the displacement field, e.g., TSDT, can be used to derive the equations of motion for thermal vibration of FGM when using a higher-order shell theory. Basically, it is interesting in the linear FSDT with the varied value effects of shear correction coefficients on air flow over the outer surface of FGM thick circular cylindrical shells under four simply supported edges, that the thermal stresses and center deflection of GDQ computational results for supersonic air flow are obtained. Two parametric effects of environmental temperature and FGM power law index on the thermal stress and center deflection of supersonic air flow over the outer surface of FGM thick circular cylindrical shells are also obtained. The advantages and disadvantages of the proposed GDQ approach compared with other existing methods are highlighted, the use of varied values for shear correction coefficients seem better than a constant shear correction value; also, the GDQ computation time is less, and some physical meanings of aero-elastic flutter and vibration research needed to be studied in the future.

The morphing aircraft (adaptive structures and smart materials) theme is one of recent advances in smart structures and multifunctional materials that has facilitated many novel aerospace technologies. Ajaj et al. [18] presented a new design philosophy for morphing aircraft technology to classify the functionality, operation, and structural layout. Additionally, the performance comparisons between morphing aircraft and conventional aircraft are provided and the morphing parameters would be improved in the future work. Hu et al. [19] presented and simulated the aero-elastic responses of the folding wing during its morphing processes, and the dynamic aero-elastic stabilities were also investigated in the folding and unfolding rates. Huang and Qiu [20] presented the numerical results of transient and flutter characteristics in a variable span morphing wing, and found the morphing technology would be used to enhance flight quality for the flutter control. Barbarino et al. [21] presented a reviewing for the morphing aircraft and focused on structural, shape-changing morphing concepts in the active systems. The morphing aircraft also has optimal aerodynamic characteristics and fuel condition for expanding the entire flight envelope within its safe performance limits. Weisshaar [22] presented the new shape changes technology in wing surface area and controlled airfoil camber for morphing aircraft design to provide high performance. Librescu et al. [23] presented and implemented the combined control law of active aero-elastic control in 2-D wing-flap systems to suppress the flutter instability. In this paper, the FGM shell might be embedded with magnetostrictive material to work as the adaptive structures; the maximum flutter value of center deflection amplitude with 
magnetostrictive FGM shell might be predicted and controlled into smaller value in supersonic air flow. The aero-elastic flutter and thermal vibration researches of magnetostrictive FGM shells might be the potential areas of application on a morphing aircraft to obtain better performances and good structures. In future works, the magnetostrictive material might be embedded in the FGM thick circular cylindrical shells and used in the body of the morphing aircraft to suppress flutter.

\section{Formulation}

For fluid flow over the outer surface of two-material FGM circular cylindrical shell is shown in Figure 1 with FGM material 1 thickness $h_{1}$ and FGM material 2 thickness $h_{2}$, respectively. The material properties of the power law function of the FGM circular cylindrical shells are considered with a dominated Young's modulus $E_{f g m}$ of the FGM in the standard variation form of the power law index $R_{n}$, and the others are assumed in the simple average form [24]. The properties of the individual constituent materials of FGMs are functions of the environmental temperature $T$.

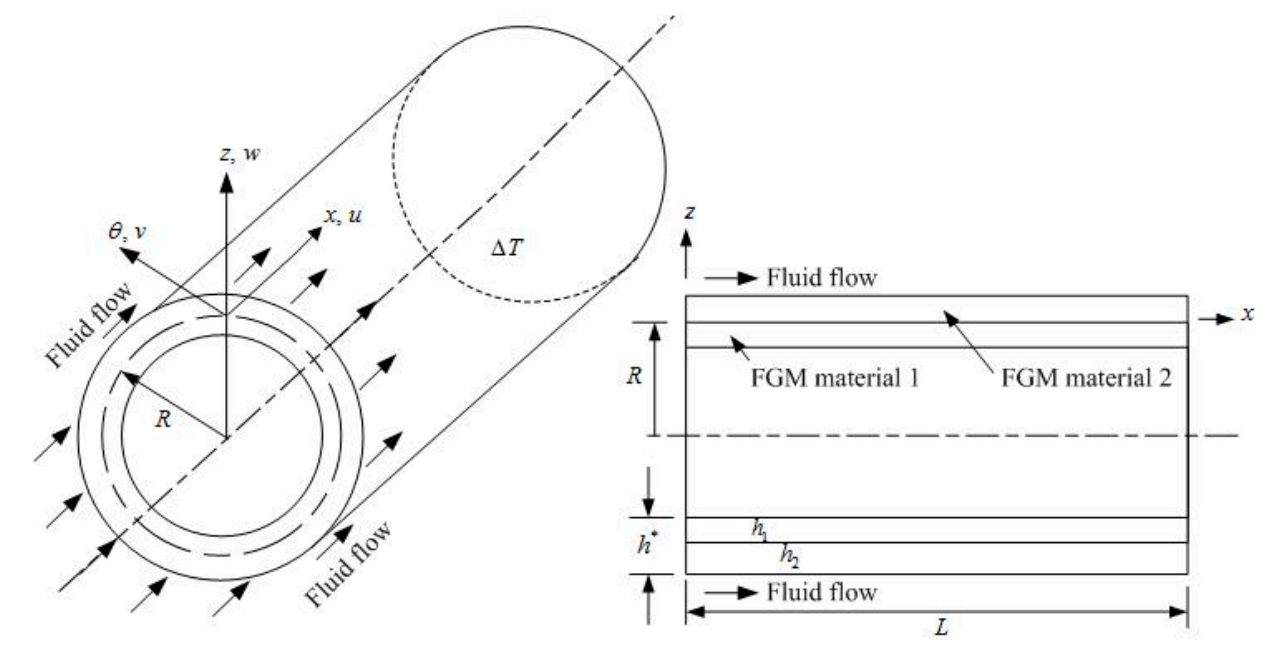

Figure 1. Fluid flow over the outer surface of two-material FGM circular cylindrical shells.

The time dependency of displacements $u, v$ and $w$ of thick circular cylindrical shells are assumed in the linear FSDT equations as follows [25]: the formulas are correct only in the case of the symmetric properties with respect to mid-plane. As one knows, density of FGMs is usually not symmetric with respect to the middle-surface; thus, the neutral surface has the role of the middle-surface and, for simplification, the middle-surface is assumed and considered near to the neutral surface of FGMs.

$$
\begin{gathered}
u=u_{0}(x, \theta, t)+z \phi_{x}(x, \theta, t) \\
v=v_{0}(x, \theta, t)+z \phi_{\theta}(x, \theta, t) \\
w=w(x, \theta, t)
\end{gathered}
$$

where $u_{0}$ and $v_{0}$ are tangential displacements, $w$ is transverse displacement of the middle-surface of the shells, $\phi_{x}$ and $\phi_{\theta}$ are middle-surface shear rotations, $x$ and $\theta$ are in-surface coordinates of the shell, $z$ is out of surface coordinates of the shell, $t$ is time.

The in-plane stresses constitute the membrane stresses, bending stresses and thermal stresses under temperature difference $\Delta T$ for the $k$ th layer of plane stresses in the thick FGM circular cylindrical shell are provided in the equations as follows $[26,27]$ :

$$
\left\{\begin{array}{c}
\sigma_{x} \\
\sigma_{\theta} \\
\sigma_{x \theta}
\end{array}\right\}_{(k)}=\left[\begin{array}{lll}
\bar{Q}_{11} & \bar{Q}_{12} & \bar{Q}_{16} \\
\bar{Q}_{12} & \bar{Q}_{22} & \bar{Q}_{26} \\
\bar{Q}_{16} & \bar{Q}_{26} & \bar{Q}_{66}
\end{array}\right]_{(k)}\left\{\begin{array}{c}
\varepsilon_{x}-\alpha_{x} \Delta T \\
\varepsilon_{\theta}-\alpha_{\theta} \Delta T \\
\varepsilon_{x \theta}-\alpha_{x \theta} \Delta T
\end{array}\right\}_{(k)}
$$


The shear stresses are provided as follows:

$$
\left\{\begin{array}{l}
\sigma_{\theta z} \\
\sigma_{x z}
\end{array}\right\}_{(k)}=\left[\begin{array}{ll}
\bar{Q}_{44} & \bar{Q}_{45} \\
\bar{Q}_{45} & \bar{Q}_{55}
\end{array}\right]_{(k)}\left\{\begin{array}{l}
\varepsilon_{\theta z} \\
\varepsilon_{x z}
\end{array}\right\}_{(k)}
$$

where $\alpha_{x}$ and $\alpha_{\theta}$ are the coefficients of thermal expansion, $\alpha_{x \theta}$ is the coefficient of thermal shear, $\bar{Q}_{i j}$ is the stiffness of the FGM shell. $\varepsilon_{x}, \varepsilon_{\theta}$, and $\varepsilon_{x \theta}$ are in-plane strains, not negligible $\varepsilon_{\theta z}$ and $\varepsilon_{x z}$ are shear strains. $k_{x}, k_{\theta}$, and $k_{x \theta}$ are the curvatures. $\Delta T$ is the temperature difference between the FGM shell and curing area can be provided in the equation as follows:

$$
\Delta T=T_{0}(x, \theta, t)+\frac{z}{h^{*}} T_{1}(x, \theta, t)
$$

in which $T_{0}$ and $T_{1}$ are temperature parameters in functions of $x, \theta$, and $t ; h^{*}$ is the total thickness of shells.

The dynamic equations of motion for a circular cylindrical shell are provided by Jafari et al. [28]. The constitutive relations including thermal loads effect is provided by Lee et al. [26]. The dynamic equilibrium differential equations of fluid flow over the outer surface of FGM circular cylindrical shells in terms of displacements and shear rotations can be provided and represented as follows:

$$
\begin{aligned}
& {\left[\begin{array}{ccccccccc}
A_{11} & 0 & A_{66} / R^{2} & 0 & \left(A_{12}+A_{66}\right) / R & 0 & 0 & 0 & 0 \\
0 & \left(A_{12}+A_{66}\right) / R & 0 & A_{66}+N_{a} & 0 & A_{22} / R & 0 & 0 & 0 \\
0 & 0 & 0 & 0 & 0 & 0 & A_{55}+N_{a} & 0 & A_{44} / R^{2} \\
B_{11} & 0 & B_{66} / R^{2} & 0 & \left(B_{12}+B_{66}\right) / R & 0 & 0 & 0 & 0 \\
0 & \left(B_{12}+B_{66}\right) / R & 0 & B_{66} & 0 & B_{22} / R^{2} & 0 & 0 & 0
\end{array}\right]}
\end{aligned}
$$

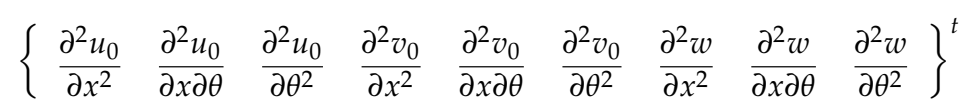

$$
\begin{aligned}
& +\left[\begin{array}{cccccc}
2 B_{11} & 0 & 2 B_{66} / R^{2} & 0 & 2\left(B_{12}+B_{66}\right) / R & 0 \\
0 & 2\left(B_{12}+B_{66}\right) / R & 0 & 2 B_{66}+M_{a} & 0 & 2 B_{22} / R^{2} \\
0 & 0 & 0 & 0 & 0 & 0 \\
2 D_{11} & 0 & 2 D_{66} / R^{2} & 0 & 2\left(D_{12}+D_{66}\right) / R & 0 \\
0 & 2\left(D_{12}+D_{66}\right) / R & 0 & 2 D_{66} & 0 & 2 D_{22} / R^{2}
\end{array}\right]
\end{aligned}
$$

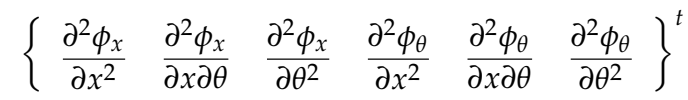

$$
\begin{aligned}
& +\left\{\begin{array}{cccccccc}
0 & 0 & A_{12} / R & 0 & 0 & 0 & 0 & 0 \\
0 & 0 & 0 & \left(A_{22}+A_{44}\right) / R^{2} & 0 & 0 & 0 & 0 \\
-A_{55} / R & -A_{44} / R^{2} & 0 & 0 & A_{55} & 0 & 0 & A_{44} / R \\
0 & 0 & B_{12} / R-A_{55} & 0 & 0 & 0 & 0 & 0 \\
0 & 0 & 0 & B_{22} / R^{2}-A_{44} / R & 0 & 0 & 0 & 0
\end{array}\right\} \\
& \left\{\begin{array}{llllllll}
\frac{\partial u_{0}}{\partial x} & \frac{\partial v_{0}}{\partial \theta} & \frac{\partial w}{\partial x} & \frac{\partial w}{\partial \theta} & \frac{\partial \phi_{x}}{\partial x} & \frac{\partial \phi_{x}}{\partial \theta} & \frac{\partial \phi_{\theta}}{\partial x} & \frac{\partial \phi_{\theta}}{\partial \theta}
\end{array}\right\}^{t} \\
& +\left[\begin{array}{ccccc}
0 & 0 & 0 & 0 & 0 \\
0 & -A_{44} / R^{2} & 0 & 0 & A_{44} / R \\
0 & 0 & 0 & 0 & 0 \\
-A_{55} / R & 0 & 0 & -A_{55} & 0 \\
0 & -A_{44} / R & 0 & 0 & -A_{44}
\end{array}\right]\left\{\begin{array}{lllll}
u_{0} & v_{0} & w & \phi_{x} & \phi_{\theta}
\end{array}\right\}^{t} \\
& =\left\{\begin{array}{l}
f_{1} \\
f_{2} \\
f_{3} \\
f_{4} \\
f_{5}
\end{array}\right\}+\rho\left[\begin{array}{lll}
1 & 0 & 0 \\
0 & 1 & 0 \\
0 & 0 & 1 \\
0 & 0 & 0 \\
0 & 0 & 0
\end{array}\right]\left\{\begin{array}{c}
\frac{\partial^{2} u_{0}}{\partial t^{2}} \\
\frac{\partial^{2} v_{0}}{\partial t^{2}} \\
\frac{\partial^{2} w}{\partial t^{2}}
\end{array}\right\}+H\left[\begin{array}{llll}
0 & 0 & 2 & 0 \\
0 & 0 & 0 & 2 \\
0 & 0 & 0 & 0 \\
1 & 0 & 0 & 0 \\
0 & 1 & 0 & 0
\end{array}\right]\left\{\begin{array}{c}
\frac{\partial^{2} u_{0}}{\partial t^{2}} \\
\frac{\partial^{2} v_{0}}{\partial t^{2}} \\
\frac{\partial^{2} \phi_{x}}{\partial t^{2}} \\
\frac{\partial^{2} \phi_{\theta}}{\partial t^{2}}
\end{array}\right\}+I\left[\begin{array}{ll}
0 & 0 \\
0 & 0 \\
0 & 0 \\
2 & 0 \\
0 & 2
\end{array}\right]\left\{\begin{array}{c}
\frac{\partial^{2} \phi_{x}}{\partial t^{2}} \\
\frac{\partial^{2} \phi_{\theta}}{\partial t^{2}}
\end{array}\right\},
\end{aligned}
$$


where $R$ is the middle-surface radius of shells. $f_{1} \ldots f_{5}$ are in the expressions of thermal loads $(\bar{N}, \bar{M})$ as follows:

$$
\begin{aligned}
& f_{1}=\frac{\partial \bar{N}_{x}}{\partial x}+\frac{1}{R} \frac{\partial \bar{N}_{x \theta}}{\partial \theta} \\
& f_{2}=\frac{\partial \bar{N}_{x \theta}}{\partial x}+\frac{1}{R} \frac{\partial \bar{N}_{\theta}}{\partial \theta} \\
& f_{3}=q-\frac{\bar{N}_{\theta}}{R} \\
& f_{4}=\frac{\partial \bar{M}_{x}}{\partial x}+\frac{1}{R} \frac{\partial \bar{M}_{x \theta}}{\partial \theta}, \\
& f_{5}=\frac{\partial \bar{M}_{x \theta}}{\partial x}+\frac{1}{R} \frac{\partial \bar{M}_{\theta}}{\partial \theta} \\
& \left(\bar{N}_{x}, \bar{M}_{x}\right)=\int_{-\frac{h^{*}}{2}}^{\frac{h^{*}}{2}}\left(\bar{Q}_{11} \alpha_{x}+\bar{Q}_{12} \alpha_{\theta}+\bar{Q}_{16} \alpha_{x \theta}\right) \Delta T(1, z) d z, \\
& \left(\bar{N}_{\theta}, \bar{M}_{\theta}\right)=\int_{\frac{-h^{*}}{2}}^{\frac{h^{*}}{2}}\left(\bar{Q}_{12} \alpha_{x}+\bar{Q}_{22} \alpha_{\theta}+\bar{Q}_{26} \alpha_{x \theta}\right) \Delta T(1, z) d z \\
& \left(\bar{N}_{x \theta}, \bar{M}_{x \theta}\right)=\int_{\frac{-h^{*}}{2}}^{\frac{h^{*}}{2}}\left(\bar{Q}_{16} \alpha_{x}+\bar{Q}_{26} \alpha_{\theta}+\bar{Q}_{66} \alpha_{x \theta}\right) \Delta T(1, z) d z, \\
& \left(A_{i j}, B_{i j}, D_{i j}\right)=\int_{\frac{-h^{*}}{2}}^{\frac{h^{*}}{2}} \bar{Q}_{i j}\left(1, z, z^{2}\right) d z,(i, j=1,2,6), \\
& A_{i^{*} j^{*}}=\int_{\frac{-h^{*}}{2}}^{\frac{h^{*}}{2}} k_{\alpha} \bar{Q}_{i^{*} j^{*}} d z,\left(i^{*}, j^{*}=4,5\right), \\
& (\rho, H, I)=\int_{\frac{-h^{*}}{2}}^{\frac{h^{*}}{2}} \rho_{0}\left(1, z, z^{2}\right) d z, \\
& \left(N_{a}, M_{a}\right)=\int_{-\frac{h^{*}}{2}}^{\frac{h^{*}}{2}}\left(\bar{Q}_{11} \alpha_{x}+\bar{Q}_{12} \alpha_{\theta}+\bar{Q}_{16} \alpha_{x \theta}\right) T_{0}(1, z) d z \\
& q=\left.\frac{\rho_{\infty} U_{\infty}^{2}}{M_{\infty}} \frac{\partial w(x, \theta, t)}{\partial x}\right|_{z=h^{*} / 2}+\frac{\rho_{\infty} U_{\infty}}{M_{\infty}} \frac{\partial w(x, \theta, t)}{\partial t},
\end{aligned}
$$

in which $k_{\alpha}$ is the shear correction coefficient. $q$ is the supersonic aerodynamic pressure load, introduced by Dowell et al. [29] for the unsteady, inviscid fluid flow over the outer surface of FGM shells with free stream density $\rho_{\infty}$, velocity $U_{\infty}$ and Mach number $M_{\infty} . \rho_{0}$ is the density of ply, $N_{a}$ and $M_{a}$ are the pulsating axial load and moment in function of $T_{0}$. The values of $k_{\alpha}$ are usually functions of $h^{*}$, $T$ and $R_{n}$. The simple forms of $\bar{Q}_{i j}$ and $\bar{Q}_{i^{*} j^{*}}$ for FGM circular cylindrical shells can be provided by Sepiani et al. [30].

The value of shear correction coefficient is usually varied in the FGM shells. The modified shear correction factor $k_{\alpha}$ can be provided based on the total strain energy equivalence principle due to transverse shears $\sigma_{x z}$ and $\sigma_{\theta z}$ by Whitney [27], and $\frac{\partial k_{x}}{\partial x}=\frac{\partial k_{\theta}}{\partial x}=\frac{\partial k_{x \theta}}{\partial x}=\frac{\partial k_{x}}{R \partial \theta}=\frac{\partial k_{\theta}}{R \partial \theta}=\frac{\partial k_{x \theta}}{R \partial \theta}$ is assumed, the expression of $k_{\alpha}$ can be obtained and represented in the following equation:

$$
k_{\alpha}=\frac{1}{h^{*}} \frac{F G M Z S V}{F G M Z I V}
$$

where the reasonable meaning of FGMZSV / FGMZIV is the effective thickness in shear correction. 


$$
\begin{gathered}
F G M Z S V=\frac{(F G M Z S)^{2}}{\left(1-v_{f g m^{2}}\right)^{2}}+\frac{v_{f g m}{ }^{2}(F G M Z S)^{2}}{\left(1-v_{f g m}\right)^{2}}+\frac{(F G M Z S)^{2}}{4\left(1+v_{f g m}\right)^{2}} \\
+2 \frac{v_{f g m}}{1-v_{f g m}{ }^{2}} \frac{(F G M Z S)^{2}}{1-v_{f g m}^{2}}+\frac{(F G M Z S)^{2}}{\left(1-v_{f g m}{ }^{2}\right)\left(1+v_{f g m}\right)} \\
+\frac{v_{f g m}}{1-v_{f g m}{ }^{2}} \frac{(F G M Z S)^{2}}{1+v_{f g m}}+\frac{(F G M Z S)^{2}}{4\left(1+v_{f g m}\right)^{2}}+\frac{v_{f g m}{ }^{2}(F G M Z S)^{2}}{\left(1-v_{f g m}\right)^{2}}+\frac{(F G M Z S)^{2}}{\left(1-v_{f g m}\right)^{2}} \\
+\frac{v_{f g m}}{1-v_{f g m}{ }^{2}} \frac{(F G M Z S)^{2}}{1+v_{f g m}}+\frac{(F G M Z S)^{2}}{\left(1+v_{f g m}\right)\left(1-v_{f g m}{ }^{2}\right)}+2 \frac{v_{f g m}}{1-v_{f g m}{ }^{2}} \frac{(F G M Z S)^{2}}{1-v_{f g m}{ }^{2}},
\end{gathered}
$$

and:

$$
\begin{gathered}
F G M Z I V=\frac{F G M Z I}{\left(1-v_{f g m}\right)^{2}}+\frac{v_{f g m}{ }^{2} F G M Z I}{\left(1-v_{f g m}\right)^{2}}+\frac{F G M Z I}{4\left(1+v_{f g m}\right)^{2}} \\
+2 \frac{v_{f g m}}{1-v_{f g m}{ }^{2}} \frac{F G M Z I}{1-v_{f g m}^{2}}+\frac{F G M Z I}{\left(1-v_{f g m}^{2}\right)\left(1+v_{f g m}\right)}+\frac{v_{f g m}}{1-v_{f g m}{ }^{2}} \frac{F G M Z I}{1+v_{f g m}}+\frac{F G M Z I}{4\left(1+v_{f g m}\right)^{2}} \\
+\frac{v_{f g m}{ }^{2} F G M Z I}{\left(1-v_{f g m}^{2}\right)^{2}}+\frac{F G M Z I}{\left(1-v_{f g m}^{2}\right)^{2}}+\frac{v_{f g m}}{1-v_{f g m}{ }^{2}} \frac{F G M Z I}{1+v_{f g m}}+\frac{F G M Z I}{\left(1+v_{f g m}\right)\left(1-v_{f g m}{ }^{2}\right)} \\
+2 \frac{v_{f g m}}{1-v_{f g m}{ }^{2}} \frac{F G M Z I}{1-v_{f g m}{ }^{2}}+\left(-\frac{E_{1} h^{* 2}}{8}\right)^{2} h^{*},
\end{gathered}
$$

in which $v_{f g m}$ is the Poisson's ratio of the FGM shells,

$$
\begin{aligned}
& \text { FGMZS }=\frac{E_{2}-E_{1}}{h^{* R_{n}}}\left[\frac{\left(\frac{h^{*}}{2}+\frac{h^{*}}{2}\right)^{R_{n}+3}}{R_{n}+3}-\frac{h^{*}\left(\frac{h^{*}}{2}+\frac{h^{*}}{2}\right)^{R_{n}+2}}{R_{n}+2}+\frac{h^{* 2}\left(\frac{h^{*}}{2}+\frac{h^{*}}{2}\right)^{R_{n}+1}}{4\left(R_{n}+1\right)}\right] \\
& +E_{1}\left[\frac{\left(\frac{h^{*}}{2}\right)^{3}}{3}-\frac{\left(-\frac{h^{*}}{2}\right)^{3}}{3}\right],
\end{aligned}
$$

and:

$$
\begin{aligned}
& \text { FGMZI }=\left(\frac{E_{2}-E_{1}}{h^{* R_{n}}}\right)^{2} \frac{\left(\frac{h^{*}}{2}+\frac{h^{*}}{2}\right)^{2 R_{n}+5}}{\left(R_{n}+2\right)^{2}\left(2 R_{n}+5\right)}-h^{*} \frac{\left(\frac{h^{*}}{2}+\frac{h^{*}}{2}\right)^{2 R_{n}+4}}{\left(R_{n}+1\right)\left(R_{n}+2\right)\left(2 R_{n}+4\right)} \\
& \left.+h^{* 2} \frac{\left(\frac{h^{*}}{2}+\frac{h^{*}}{2}\right)^{2 R_{n}+3}}{4\left(R_{n}+1\right)^{2}\left(2 R_{n}+3\right)}\right]+\frac{2\left(E_{2}-E_{1}\right)}{h^{* R_{n}}}\left\{\frac { E _ { 1 } } { 2 ( R _ { n } + 2 ) } \left[\frac{\left(\frac{h^{*}}{2}+\frac{h^{*}}{2}\right)}{R_{n}+5}\right.\right. \\
& \left.-h^{*} \frac{\left(\frac{h^{*}}{2}+\frac{h^{*}}{2}\right)^{R_{n}+4}}{R_{n}+4}+\frac{h^{* 2}}{4} \frac{\left(\frac{h^{*}}{2}+\frac{h^{*}}{2}\right)^{R_{n}+3}}{R_{n}+3}\right]-\frac{h^{*} E_{1}}{4\left(R_{n}+1\right)}\left[\frac{\left(\frac{h^{*}}{2}+\frac{h^{*}}{2}\right)^{R_{n}+4}}{R_{n}+4}\right. \\
& \left.\left.-h^{*} \frac{\left(\frac{h^{*}}{2}+\frac{h^{*}}{2}\right)^{R_{n}+3}}{R_{n}+3}+\frac{h^{* 2}}{4} \frac{\left(\frac{h^{*}}{2}+\frac{h^{*}}{2}\right)^{R_{n}+2}}{R_{n}+2}\right]\right\}+\frac{E_{1}^{2} h^{* 5}}{320}+2\left(-\frac{E_{1} h^{* 2}}{8}\right) \\
& \left\{\frac{E_{2}-E_{1}}{h^{* R_{n}}}\left[\frac{\left(\frac{h^{*}}{2}+\frac{h^{*}}{2}\right)}{\left(R_{n}+2\right)\left(R_{n}+3\right)}-h^{*} \frac{\left(\frac{h^{*}}{2}+\frac{h^{*}}{2}\right)}{2\left(R_{n}+1\right)\left(R_{n}+2\right)}\right]+\frac{E_{1} h^{* 3}}{24}\right\} .
\end{aligned}
$$


Shu and Richards presented the GDQ method in 1990 and re-stated the statements as follows: the derivative of a smooth function at a discrete point in a domain can be discrete by using an approximated weighting linear sum of the function values at all of the discrete points in the direction of axes $[16,31,32]$. The dynamic GDQ discrete equations in matrix notation can be provided in the formulation of dynamic equilibrium differential equations by considering four sides, simply supported, and fluid flow over the outer surface of FGM thick circular cylindrical shells.

\section{Numerical Results and Discussion}

There are some real applications of considered structures in Figure 1, e.g., fluid flow over the outer surface of missiles, rockets, and airplanes. To study the GDQ results of varied shear correction coefficient calculations with shell layers in the stacking sequence $\left(0^{\circ} / 0^{\circ}\right)$, for the four sides simply supported boundary condition, no pulsating axial load and moment $\left(N_{a}=M_{a}=0\right)$, and under the external aerodynamic pressure load $(q)$ of supersonic air flow over the outer surface of FGM shells with $\rho_{\infty}=0.00000678 \mathrm{lb} / \mathrm{in}^{3}$, at altitude $50,000 \mathrm{ft}$, respectively for $M_{\infty}=2\left(U_{\infty}=23,304 \mathrm{in} / \mathrm{s}\right)$, for $M_{\infty}=4\left(U_{\infty}=46,608 \mathrm{in} / \mathrm{s}\right)$ and for $M_{\infty}=10\left(U_{\infty}=116,520 \mathrm{in} / \mathrm{s}\right)$, the coordinates $x_{i}$ and $\theta_{j}$ for the grid points of FGM thick circular cylindrical shells are used as follows:

$$
\begin{gathered}
x_{i}=0.5\left[1-\cos \left(\frac{i-1}{N-1} \pi\right)\right] L, i=1,2, \cdots, N, \\
\theta_{j}=0.5\left[1-\cos \left(\frac{j-1}{M-1} \pi\right)\right] 2 \pi, j=1,2, \cdots, M .
\end{gathered}
$$

Sinusoidal displacement and temperature of the thermal vibrations are provided as follows:

$$
\begin{gathered}
u=\left[u_{0}(x, \theta)+z \phi_{x}(x, \theta)\right] \sin \left(\omega_{m n} t\right), \\
v=\left[v_{0}(x, \theta)+z \phi_{\theta}(x, \theta)\right] \sin \left(\omega_{m n} t\right), \\
w=w(x, \theta) \sin \left(\omega_{m n} t\right), \\
\phi_{x}=\phi_{x}(x, \theta) \sin \left(\omega_{m n} t\right), \\
\phi_{\theta}=\phi_{\theta}(x, \theta) \sin \left(\omega_{m n} t\right), \\
\Delta T=\left[T_{0}(x, \theta)+\frac{z}{h^{*}} T_{1}(x, \theta)\right] \sin (\gamma t) .
\end{gathered}
$$

and with the simple vibration of temperature parameter:

$$
\begin{gathered}
T_{0}(x, \theta)=0,\left(N_{a}=M_{a}=0\right), \\
T_{1}(x, \theta)=\bar{T}_{1} \sin (\pi x / L) \sin (\pi \theta),
\end{gathered}
$$

in which $\omega_{m n}$ is the natural frequency of the shells, $\gamma$ is the frequency of applied heat flux, and $\bar{T}_{1}$ is the amplitude of temperature.

Two constituent materials of FGMs are provided. FGM material 1 is SUS304 (stainless steel), FGM material 2 is $\mathrm{Si}_{3} \mathrm{~N}_{4}$ (silicon nitride), used for the numerical GDQ computations. The dimensional quantities are used for each example cases, units in $\mathrm{mm}$ are used in the deflection amplitude and thickness, and $\mathrm{GP}_{\mathrm{a}}$ used for stress. Firstly, the dynamic convergence study of center deflection amplitude $w(L / 2,2 \pi / 2)$ (unit $\mathrm{mm}$ ) versus $N=M$ in a supersonic air flow $M_{\infty}=2,4$, and 10, respectively, over the outer surface of circular cylindrical FGM shells are obtained in Figure 2 by considering the varied effects of shear correction coefficients and with $L / R=2, L / h^{*}=5$, $h^{*}=1.2 \mathrm{~mm}, h_{1}=h_{2}=0.6 \mathrm{~mm}, m=n=1, R_{n}=1, k_{\alpha}=0.101452, T=653 \mathrm{~K}, \bar{T}_{1}=1 \mathrm{~K}$, and $t=0.1 \mathrm{~s}$. The $N \times M=19 \times 19$ grid points can be treated in the convergence status and used in the following GDQ computations of time responses for deflection and stress in a supersonic air flow 
over the outer surface of circular cylindrical FGM shells. In the circular cylindrical FGM shell $\left(B_{i j} \neq 0\right)$, varied values of $k_{\alpha}$ are usually functions of $h^{*}, R_{n}$ and $T$. For $h^{*}=1.2 \mathrm{~mm}, h_{1}=h_{2}$, calculated values of $k_{\alpha}$ versus $R_{n}$ and $T$ are shown in Table 1, used for the GDQ and shear calculations. For $h^{*}=1.2 \mathrm{~mm}$, values of $k_{\alpha}$ (from 0.06616 to 0.201838 under $T=653 \mathrm{~K}$, from 0.0877684 to 0.229368 under $T=100 \mathrm{~K}$, from 0.059168 to 0.167052 under $T=1000 \mathrm{~K}$ ) are increasing with $R_{n}$ (from 0.1 to 10 ).

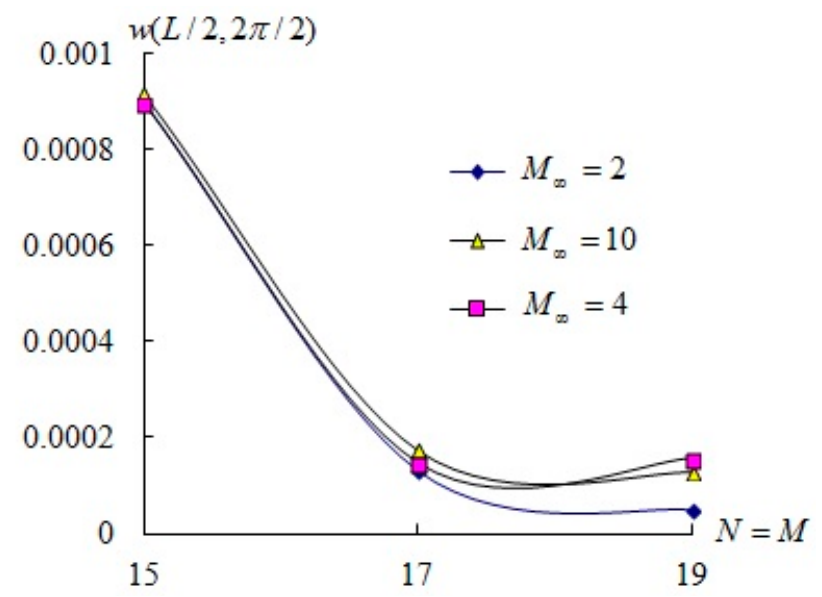

Figure 2. Convergence of $w(L / 2,2 \pi / 2)(\mathrm{mm})$ versus $N=M$ for $L / h^{*}=5$ and $L / R=2$.

Table 1. Varied shear correction coefficient $k_{\alpha}$ versus $R_{n}$ and $T$ for $h^{*}=1.2 \mathrm{~mm}$.

\begin{tabular}{cccccccc}
\hline \multirow{2}{*}{$(\mathbf{K})$} & \multicolumn{8}{c}{$\boldsymbol{k}_{\boldsymbol{\alpha}}$} \\
\cline { 2 - 8 } & $\boldsymbol{R}_{\boldsymbol{n}}=\mathbf{0 . 1}$ & $\boldsymbol{R}_{\boldsymbol{n}}=\mathbf{0 . 2}$ & $\boldsymbol{R}_{\boldsymbol{n}}=\mathbf{0 . 5}$ & $\boldsymbol{R}_{\boldsymbol{n}}=\mathbf{1}$ & $\boldsymbol{R}_{\boldsymbol{n}}=\mathbf{2}$ & $\boldsymbol{R}_{\boldsymbol{n}}=\mathbf{5}$ & $\boldsymbol{R}_{\boldsymbol{n}}=\mathbf{1 0}$ \\
\hline 100 & 0.0877684 & 0.0914646 & 0.104760 & 0.129271 & 0.171357 & 0.223472 & 0.229368 \\
653 & 0.0661600 & 0.0693373 & 0.0805978 & 0.101452 & 0.138729 & 0.190785 & 0.201838 \\
1000 & 0.0591680 & 0.0606934 & 0.0676897 & 0.0831104 & 0.113958 & 0.160412 & 0.167052 \\
\hline
\end{tabular}

The compared results of frequencies $\left(10 f^{*}\right.$ and $\Omega$ ) versus $n$ are re-plotted in Figure 3, provided and represented with the varied correction factor value 0.101452 calculated by Hong [33] and with the constant correction factor value $5 / 6=0.833333$ by Sepiani et al. [30]. The results can be treated as the similar tendency between the two curves of different frequency parameters $\left(10 f^{*}\right.$ and $\Omega$ ) versus $n$, where $f^{*}=4 \pi \omega_{m n} R \sqrt{I / A_{11}}$ with $A_{11}=\frac{h^{*}}{1-\left(\frac{v_{1}+v_{2}}{2}\right)^{2}}\left(\frac{R_{n} E_{1}+E_{2}}{R_{n}+1}\right)$, in which $E_{1}$ and $E_{2}$ are the Young's modulus, $v_{1}$ and $v_{2}$ are the Poisson's ratios of the FGM constituent material 1 and 2, respectively. $\Omega=4 \pi \omega_{m n} R \sqrt{I_{1} / A_{11 e f f}}$, where $A_{11 e f f}=\int_{-\frac{h^{*}}{2}}^{\frac{h^{*}}{2}} Q_{11} d z, I_{1}=\int_{-\frac{h^{*}}{2}}^{\frac{h^{*}}{2}} z \rho(z) d z, Q_{11}=\frac{E_{e f f}}{1-v_{e f f}^{2}}$ with $\rho(z)$, $E_{e f f}$, and $v_{e f f}$ are effective mass density, effective elastic modulus and effective Poisson's ratio of FGM, respectively, for a simply supported silicon nitride-nickel FGM cylindrical shell with FSDT under axial extensional loading and no external pressure $(q=0)$. 


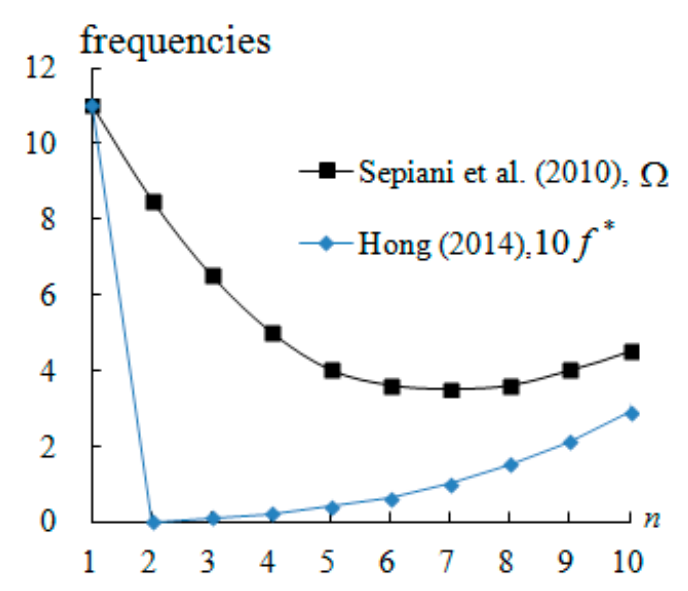

Figure 3. Compared frequency values $\left(10 f^{*}\right.$ and $\Omega$ ) versus $n$.

The amplitude of center deflection $w(L / 2,2 \pi / 2)$ (unit $\mathrm{mm}$ ) for the air flow over the outer surface of FGM circular cylindrical shells is calculated. The response values of amplitude $w(L / 2,2 \pi / 2)$ (unit $\mathrm{mm}$ ) versus time $t$ (unit s) are shown in Figure 4 for a supersonic air flow $M_{\infty}=2,4$, and 10, respectively, over the outer surface of the FGM circular cylindrical shells for thick $L / h^{*}=5, L / R=2$, $h^{*}=1.2, h_{1}=h_{2}=0.6, R_{n}=1, k_{\alpha}=0.101452, T=653 \mathrm{~K}, \bar{T}_{1}=1 \mathrm{~K}$, flutter starting time $t=0.001 \mathrm{~s}$ $(\gamma=296,881 / \mathrm{s})$, and response time $t=0.1$ to $3.0 \mathrm{~s}$ with a time step of $0.1 \mathrm{~s}$. The maximum value of amplitude $w(L / 2,2 \pi / 2)$ (unit $\mathrm{mm}$ ) is, respectively, value $10,053 \mathrm{~mm}$ occurs at $t=0.001 \mathrm{~s}$ for $M_{\infty}=2$, value $-3753 \mathrm{~mm}$ occurs at $t=1.0 \mathrm{~s}(\gamma=1.5708 / \mathrm{s})$ for $M_{\infty}=2$, value $17,842 \mathrm{~mm}$ occurs at $t=0.001 \mathrm{~s}$ for $M_{\infty}=4$, value $-4457 \mathrm{~mm}$ occurs at $t=1.0 \mathrm{~s}$ for $M_{\infty}=4$, value $12,368 \mathrm{~mm}$ occurs at $t=0.001 \mathrm{~s}$ for $M_{\infty}=10$, value $-4189 \mathrm{~mm}$ occurs at $t=1.0 \mathrm{~s}$ for $M_{\infty}=10$. Flutter occurs at $t=0.001 \mathrm{~s}$ due to high frequency of applied heat flux value $\gamma=296,881 / \mathrm{s}$ for a supersonic air flow $M_{\infty}=2,4$, and 10 . There exists a "jumping" around $t=1.0 \mathrm{~s}$, the nature of such phenomenon might be considered as, and related to, a transonic dip. The abrupt change in time responses of displacement is shock wave vibration occurred at $t=1.0 \mathrm{~s}$ in the unsteady air flow shown in Figure $4 \mathrm{a}-\mathrm{c}$, corresponding to the position in a steady air flow $M_{\infty}=2$ and without air flow $(q=0)$ are shown in Figure $4 \mathrm{~d}-\mathrm{e}$, respectively. The transient value of $11,133 \mathrm{~mm}$ in steady air flow occurs at $t=0.001 \mathrm{~s}$ is greater than $10,053 \mathrm{~mm}$ in unsteady air flow, but the value $-3753 \mathrm{~mm}$ in steady air flow occurs at $t=1.0 \mathrm{~s}$ is in the same value as in unsteady air flow. With the effects of thermal load vibrations and environment temperature only (without air flow), the transient value $6.8 \mathrm{~mm}$ occurs at $t=0.001 \mathrm{~s}$, and the value $0.008 \mathrm{~mm}$ occurs at $t=1.0 \mathrm{~s}$ are found in smaller values. Thus, the "jumping" of amplitudes around $t=1.0 \mathrm{~s}$ is due to the effect of air flow pressure and comes from the effect of shockwave vibrations.

In-plane stress $\sigma_{\theta}$ (unit $\mathrm{GP}_{\mathrm{a}}$ ) and shear stress $\sigma_{\theta z}$ (unit $\mathrm{GP}_{\mathrm{a}}$ ) are three-dimensional components and usually in functions of $x, \theta$, and $z$. Typically, their values vary through the shell thickness for the air flow over the outer surface of FGM circular cylindrical shells. The in-plane stress $\sigma_{\theta}$ (unit GP $\mathrm{a}_{\mathrm{a}}$ ) versus $z / h^{*}$ for $M_{\infty}=2$ is shown in Figure 5a. The shear stress $\sigma_{\theta z}$ (unit GP ${ }_{\mathrm{a}}$ ) versus $z / h^{*}$ for $M_{\infty}=2$ at center position $(x=L / 2, \theta=2 \pi / 2)$ of shells is shown in Figure $5 \mathrm{~b}$, respectively at $t=1.0 \mathrm{~s}, a / h^{*}=5$ and $L / R=2$. The absolute value $\left(0.0081 \mathrm{GP}_{\mathrm{a}}\right)$ of $\sigma_{\theta z}$ at $z=0.5 h^{*}$ is found in the much greater value than the value $\left(0.00681 \mathrm{GP}_{\mathrm{a}}\right)$ of $\sigma_{\theta}$ for $z=0.0 h^{*}$; thus, the $\sigma_{\theta z}$ can be treated as the dominated stress for the air flow over the outer surface of FGM circular cylindrical shells. The time responses of the dominated shear stresses $\sigma_{\theta z}$ (unit $\mathrm{GP}_{\mathrm{a}}$ ) are shown in Figure $5 \mathrm{c}-\mathrm{e}$ at the center position of the outer surface $z=0.5 h^{*}$ as the analyses of the deflection cases in Figure 4 for $L / h^{*}=5, L / R=2$, air flow $M_{\infty}=2,4$, and 10, respectively. The maximum absolute value of $\sigma_{\theta z}$ is $0.0137 \mathrm{GP}_{\mathrm{a}}$ occurs at $t=1.0 \mathrm{~s}$ for $M_{\infty}=4$. 


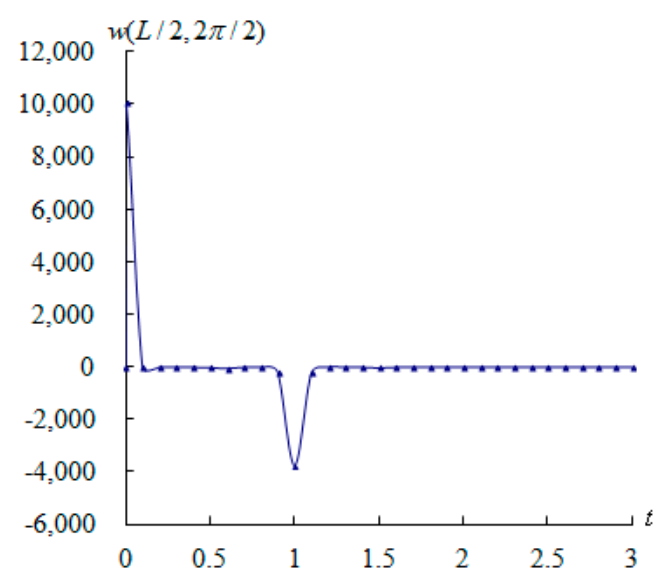

(a)

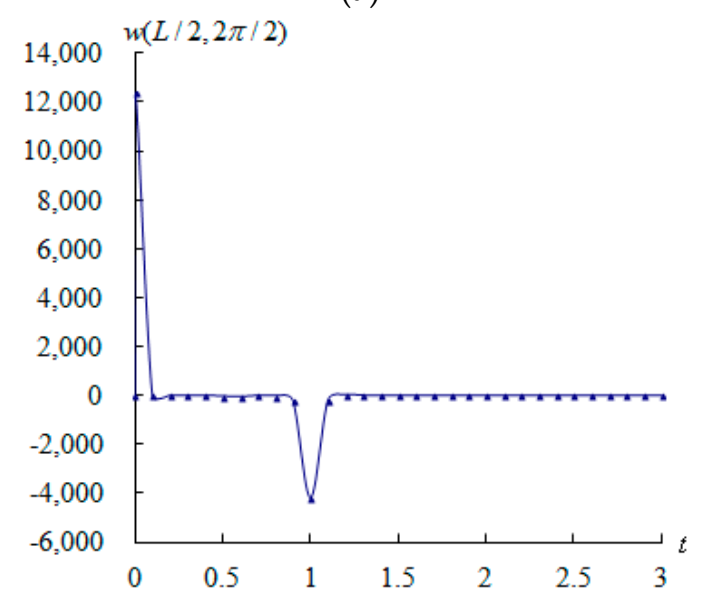

(c)

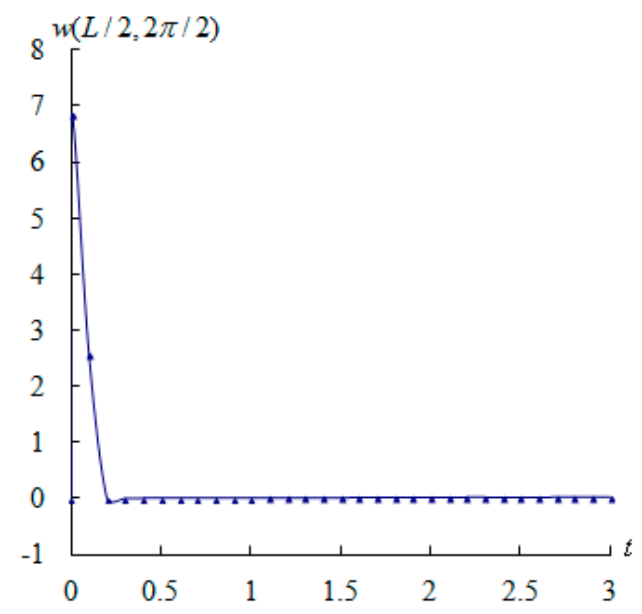

(e)

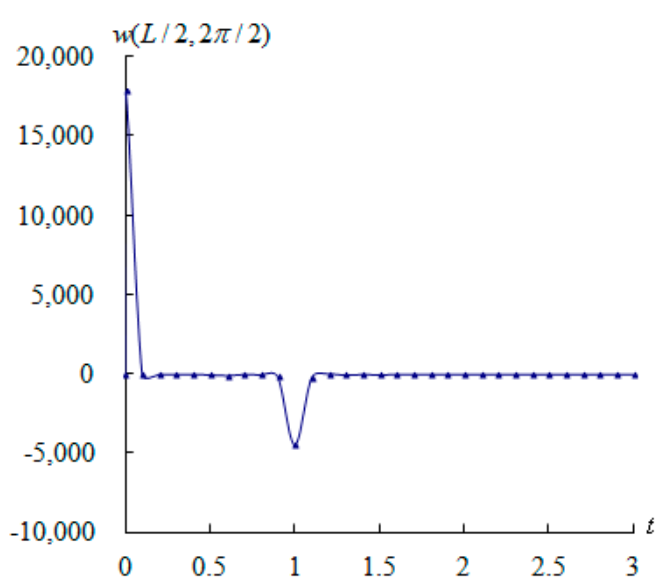

(b)

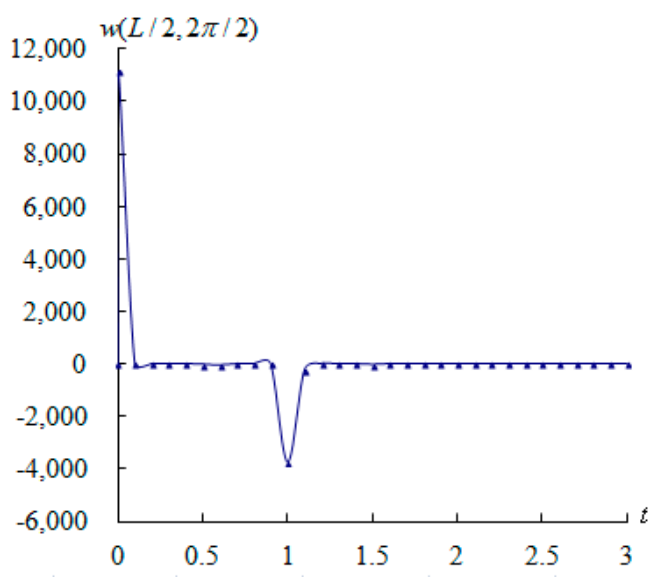

(d)

Figure 4. $w(L / 2,2 \pi / 2)(\mathrm{mm})$ versus $t$ (s) for $M_{\infty}=2,4$ and 10: (a) $w(L / 2,2 \pi / 2)(\mathrm{mm})$ versus $t$ (s) for $M_{\infty}=2 ;(\mathbf{b}) w(L / 2,2 \pi / 2)(\mathrm{mm})$ versus $t$ (s) for $M_{\infty}=4 ;$ (c) $w(L / 2,2 \pi / 2)(\mathrm{mm})$ versus $t$ (s) for $M_{\infty}=10 ;(\mathbf{d})$ for $M_{\infty}=2$ in steady flow; and (e) without air flow. 


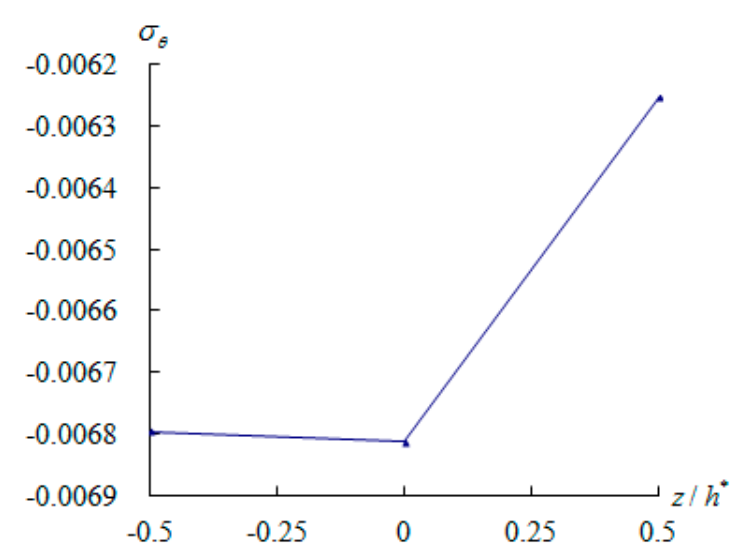

(a)

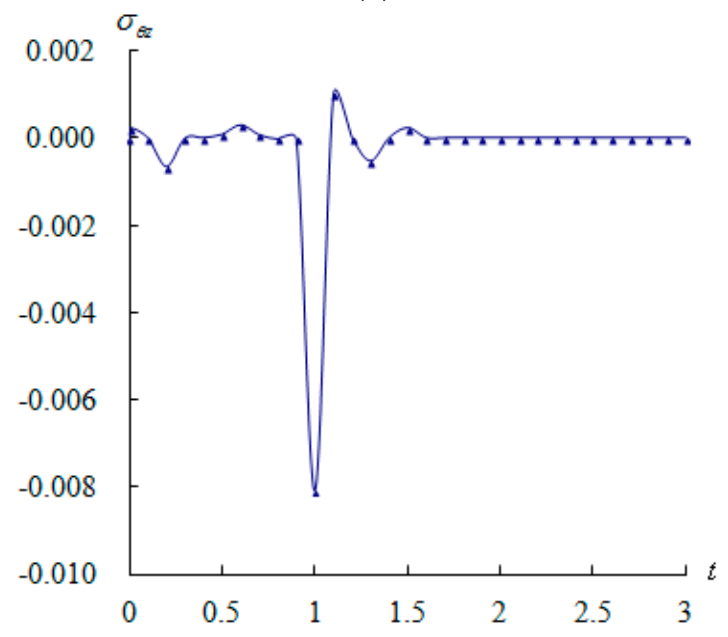

(c)

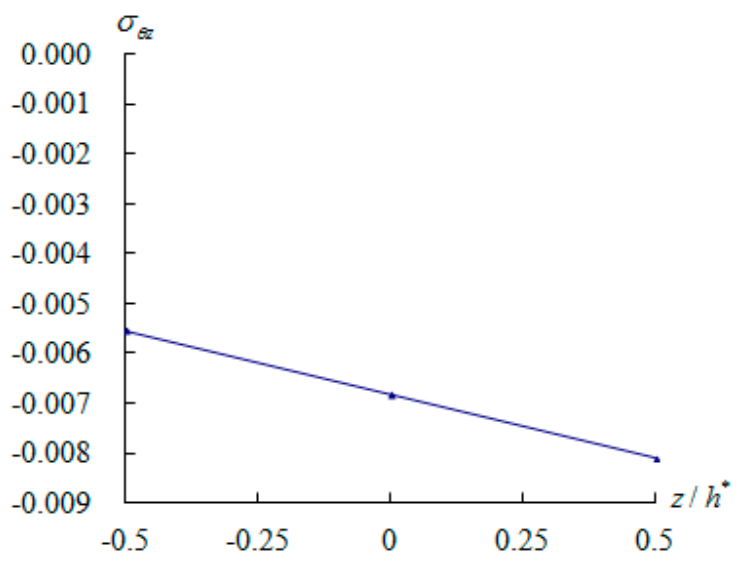

(b)

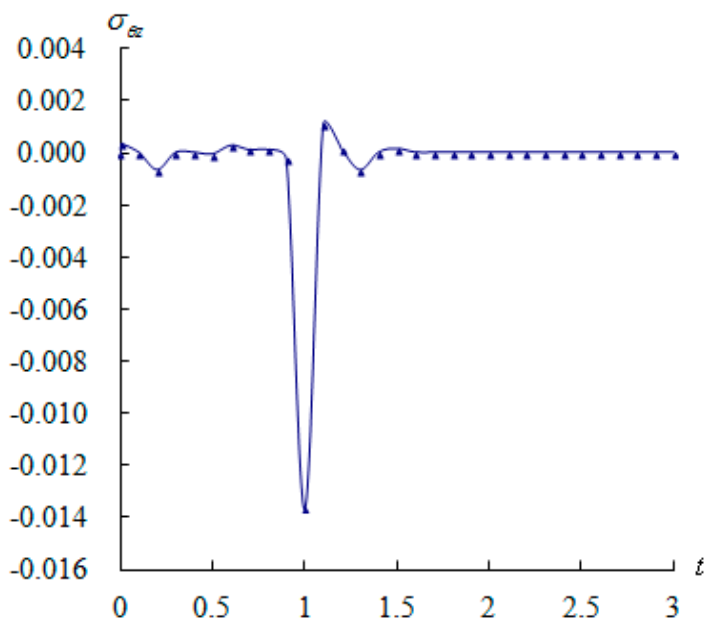

(d)

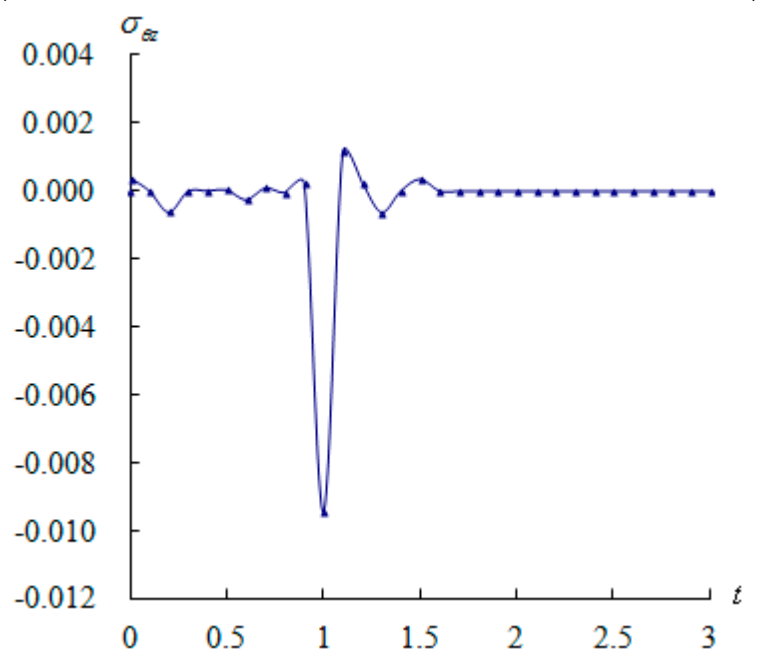

(e)

Figure 5. Stresses versus $z / h^{*}$ and $t$ for $M_{\infty}=2,4$ and 10: (a) $\sigma_{\theta}\left(\mathrm{GP}_{\mathrm{a}}\right)$ versus $z / h^{*}$ for $M_{\infty}=2$ at $t=1.0 \mathrm{~s} ;(\mathbf{b}) \sigma_{\theta z}\left(\mathrm{GP}_{\mathrm{a}}\right)$ versus $z / h^{*}$ for $M_{\infty}=2$ at $t=1.0 \mathrm{~s} ;(\mathbf{c}) \sigma_{\theta z}\left(\mathrm{GP}_{\mathrm{a}}\right)$ versus $t$ (s) for $M_{\infty}=2 ;(\mathbf{d}) \sigma_{\theta z}$ $\left(\mathrm{GP}_{\mathrm{a}}\right)$ versus $t(\mathrm{~s})$ for $M_{\infty}=4 ;(\mathbf{e}) \sigma_{\theta z}\left(\mathrm{GP}_{\mathrm{a}}\right)$ versus $t(\mathrm{~s})$ for $M_{\infty}=10$.

The amplitudes $w(L / 2,2 \pi / 2)$ (unit $\mathrm{mm}$ ) versus $T$ (unit $\mathrm{K}$ ) and $R_{n}$ values (from 0.1 to 10 ) are shown in Figure 6 for air flow $M_{\infty}=2,4$, and 10, respectively, over the outer surface of FGM circular cylindrical shells calculated and varied values of $k_{\alpha}$, for $L / h^{*}=5, L / R=2, h^{*}=1.2$, $h_{1}=h_{2}=0.6, \bar{T}_{1}=1 \mathrm{~K}$, at $t=3 \mathrm{~s}(\gamma=0.523603 / \mathrm{s})$. The maximum value of amplitude $w(L / 2,2 \pi / 2)$ 
is $1.91346 \mathrm{~mm}$ occurs at $T=100 \mathrm{~K}$ and $R_{n}=0.2$ for $M_{\infty}=2$ is shown in Figure 6a. The amplitude $w(L / 2,2 \pi / 2)$ values are all decreasing versus $T$ for values $R_{n}=0.2$ and 2 , and they can withstand higher environmental temperature $(T=1000 \mathrm{~K})$. The amplitude $w(L / 2,2 \pi / 2)$ value is decreasing (from $-1.91346 \mathrm{~mm}$ to $0.0000066 \mathrm{~mm}$ ) versus $T$ for the dominated value $R_{n}=0.2$, and it can withstand higher environmental temperature $(T=1000 \mathrm{~K})$. The maximum value of amplitude $w(L / 2,2 \pi / 2)$ is $1.03639 \mathrm{~mm}$, occurring at $T=100 \mathrm{~K}$ and $R_{n}=2$ for $M_{\infty}=4$, is shown in Figure $6 \mathrm{~b}$. The amplitude $w(L / 2,2 \pi / 2)$ values are all decreasing versus $T$ for values $R_{n}=0.2$ and 2 , they can withstand higher environmental temperature $(T=1000 \mathrm{~K})$. The amplitude $w(L / 2,2 \pi / 2)$ value is decreasing (from $1.03639 \mathrm{~mm}$ to $0.0000273 \mathrm{~mm}$ ) versus $T$ for the dominated value $R_{n}=2$, and it can withstand higher environmental temperature $(T=1000 \mathrm{~K})$. The maximum value of amplitude $w(L / 2,2 \pi / 2)$ is $2.65509 \mathrm{~mm}$, occurring at $T=100 \mathrm{~K}$ and $R_{n}=2$ for $M_{\infty}=10$, is shown in Figure 6c. The amplitude $w(L / 2,2 \pi / 2)$ values are all decreasing versus $T$ for values $R_{n}=0.2$ and 2 , and they can withstand higher environmental temperature $(T=1000 \mathrm{~K})$. The amplitude $w(L / 2,2 \pi / 2)$ value is decreasing (from 2.65509 to $0.0000271 \mathrm{~mm}$ ) versus $T$ for the dominated value $R_{n}=2$, and it can withstand for higher environmental temperature $(T=1000 \mathrm{~K})$.

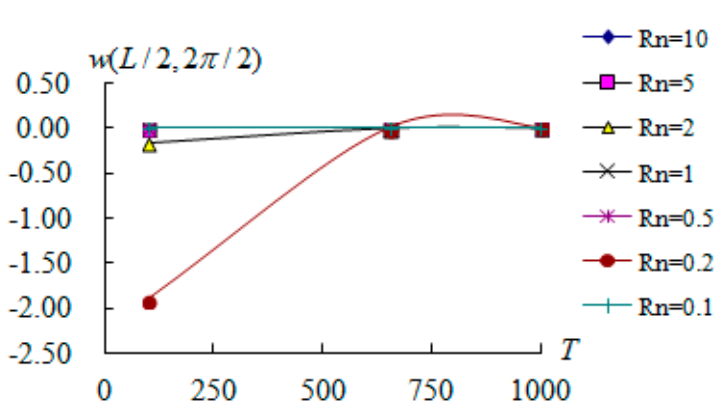

(a)

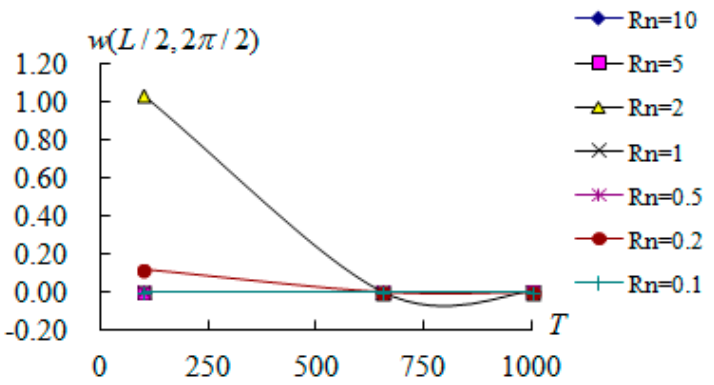

(b)

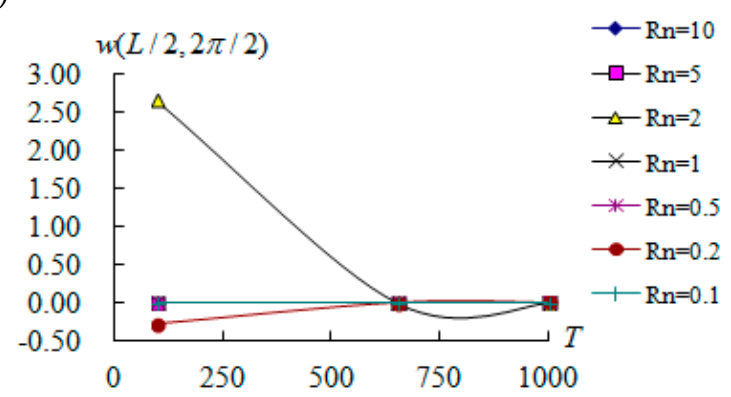

(c)

Figure 6. $w(L / 2,2 \pi / 2)(\mathrm{mm})$ versus $T(\mathrm{~K})$ and $R_{n}$ for $M_{\infty}=2,4$, and 10: (a) $w(L / 2,2 \pi / 2)(\mathrm{mm})$ versus $T(\mathrm{~K})$ and $R_{n}$ for $M_{\infty}=2$; (b) $w(L / 2,2 \pi / 2)(\mathrm{mm})$ versus $T(\mathrm{~K})$ and $R_{n}$ for $M_{\infty}=4$; and (c) $w(L / 2,2 \pi / 2)(\mathrm{mm})$ versus $T(\mathrm{~K})$ and $R_{n}$ for $M_{\infty}=10$.

The shear stress $\sigma_{\theta z}$ (unit $\mathrm{GP}_{\mathrm{a}}$ ) at center position of outer surface $z=0.5 h^{*}$ versus $T$ (unit $\mathrm{K}$ ) and $R_{n}$ are shown in Figure 7 for air flow $M_{\infty}=2,4$, and 10, respectively, over the outer surface of the FGM circular cylindrical shells as the analyses of deflection case in Figure 6. The maximum value of $\sigma_{\theta z}$ is $0.000281 \mathrm{GP}_{\mathrm{a}}$, occurring at $T=100 \mathrm{~K}$ and $R_{n}=2$ for $M_{\infty}=2$, is shown in Figure 7a. The absolute values of $\sigma_{\theta z}$ are all decreasing versus $T$ for $R_{n}=0.2$ and 2, they can withstand higher environmental temperature $(T=1000 \mathrm{~K})$. The maximum value of $\sigma_{\theta z}$ is $0.000247 \mathrm{GP}_{\mathrm{a}}$, occurring at $T=100 \mathrm{~K}$ and $R_{n}=2$ for $M_{\infty}=4$ is shown in Figure $7 \mathrm{~b}$. The absolute values of $\sigma_{\theta z}$ are all decreasing versus $T$ for $R_{n}=0.2$ and 2 , they can withstand for higher temperature $(T=1000 \mathrm{~K})$ of environment. The maximum value of $\sigma_{\theta z}$ is $0.000267 \mathrm{GP}_{\mathrm{a}}$ occurs at $T=100 \mathrm{~K}$ and $R_{n}=2$ for $M_{\infty}=10$ is shown in Figure 7c. The absolute values of $\sigma_{\theta z}$ are decreasing versus $T$ for $R_{n}=2$, and they can withstand higher environmental temperature $(T=1000 \mathrm{~K})$. 


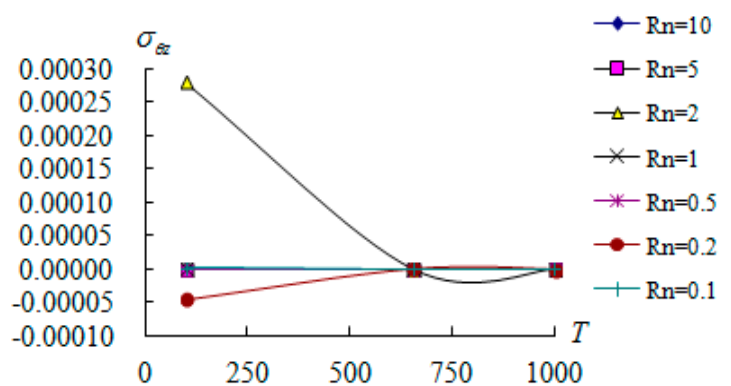

(a)

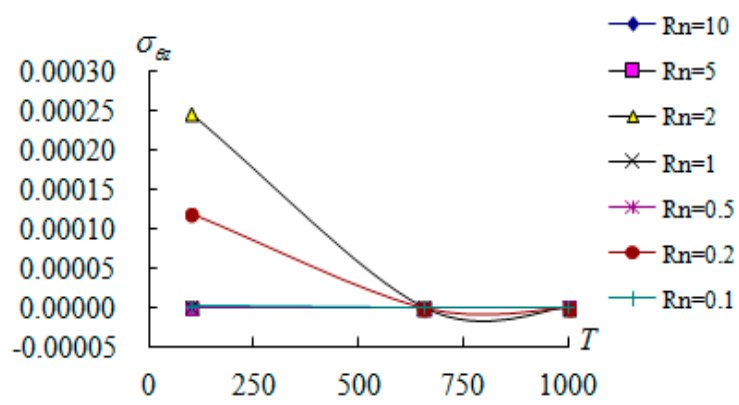

(b)

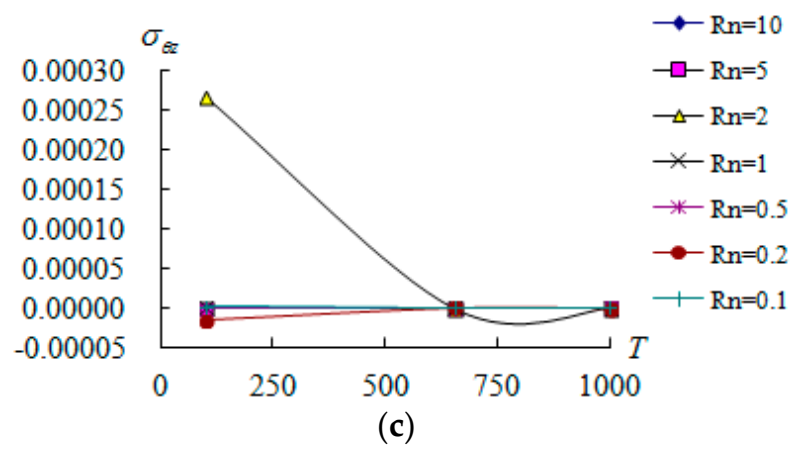

Figure 7. $\sigma_{\theta z}\left(\mathrm{GP}_{\mathrm{a}}\right)$ versus $T(\mathrm{~K})$ and $R_{n}$ for $M_{\infty}=2,4$, and 10: (a) $\sigma_{\theta z}\left(\mathrm{GP}_{\mathrm{a}}\right)$ versus $T(\mathrm{~K})$ and $R_{n}$ for $M_{\infty}=2 ;(\mathbf{b}) \sigma_{\theta z}\left(\mathrm{GP}_{\mathrm{a}}\right)$ versus $T(\mathrm{~K})$ and $R_{n}$ for $M_{\infty}=4$; and (c) $\sigma_{\theta z}\left(\mathrm{GP}_{\mathrm{a}}\right)$ versus $T(\mathrm{~K})$ and $R_{n}$ for $M_{\infty}=10$.

\section{Conclusions}

The GDQ solutions are provided for the deflections and stresses in the thermal vibration for supersonic air flow with Mach numbers 2, 4, and 10 over the outer surface of FGM thick circular cylindrical shells by considering the varied values effects of shear correction coefficient. In the GDQ results, shear correction coefficient values are usually functions of total thickness, power law index, and environment temperature. The maximum flutter value of center deflection amplitude can be predicted and occurs at high frequency of applied heat flux for supersonic air flow. The maximum value of the center deflection amplitude can be found and occurs at highly supersonic air flow. The center deflection amplitude values are all decreasing versus $T$ for values $R_{n}=0.2$ and 2 , and they also can withstand higher environmental temperature. Some physical meanings of aero-elastic flutter and vibration research are needed to be studied in the future.

Conflicts of Interest: The author declares no conflict of interest.

\section{References}

1. Samadpour, M.; Asadi, H.; Wang, Q. Nonlinear aero-thermal flutter postponement of supersonic laminated composite beams with shape memory alloys. Eur. J. Mech. A Solids 2016, 57, 18-28. [CrossRef]

2. Liu, Y.Z.; Hao, Y.X.; Zhang, W.; Chen, J.; Li, S.B. Nonlinear dynamics of initially imperfect functionally graded circular cylindrical shell under complex loads. J. Sound Vib. 2015, 348, 294-328. [CrossRef]

3. Li, J.; Narita, Y. Multi-objective design for aeroelastic flutter of laminated shallow shells under variable flow angles. Compos. Struct. 2014, 111, 530-539. [CrossRef]

4. Alijani, F.; Amabili, M. Non-linear vibrations of shells: A literature review from 2003 to 2013. Int. J. Non-Linear Mech. 2014, 58, 233-257. [CrossRef]

5. Amabili, M.; Pellicano, F.; Paidoussis, M.P. Non-linear dynamics and stability of circular cylindrical shells conveying flowing fluid. Comput. Struct. 2002, 80, 899-906. [CrossRef]

6. Kiiko, I.A. Formulation of the problem of the flutter of a shell of revolution and a shallow shell in a high-velocity supersonic gas flow. J. Appl. Math. Mech. 1999, 63, 305-312. [CrossRef] 
7. Yin, S.; Yu, T.; Bui, T.Q.; Zheng, X.; Tanaka, S. In-plane material inhomogeneity of functionally graded plates: A higher-order shear deformation plate isogeometric analysis. Compos. B Eng. 2016, 106, 273-284. [CrossRef]

8. Bui, T.Q.; Do, T.V.; Ton, L.H.T.; Doan, D.H.; Tanaka, S.; Pham, D.T.; Nguyen-Van, T.-A.; Yu, T.; Hirose, S. On the high temperature mechanical behaviors analysis of heated functionally graded plates using FEM and a new third-order shear deformation plate theory. Compos. B Eng. 2016, 92, 218-241. [CrossRef]

9. Sun, J.; Xu, X.; Lim, C.W. Torsional buckling of functionally graded cylindrical shells with temperature-dependent properties. Int. J. Struct. Stab. Dyn. 2014, 14, 1350048. [CrossRef]

10. Yin, S.; Hale, J.S.; Yu, T.; Bui, T.Q.; Bordas, S.P.A. Isogeometric locking-free plate element: A simple first order shear deformation theory for functionally graded plates. Compos. Struct. 2014, 118, 121-138. [CrossRef]

11. Ramos, I.A.; Mantari, J.L.; Zenkour, A.M. Laminated composite plates subject to thermal load using trigonometrical theory based on Carrera Unified Formulation. Compos. Struct. 2016, 143, 324-335. [CrossRef]

12. Mantari, J.L.; Ramos, I.A.; Carrera, E.; Petrolo, M. Static analysis of functionally graded plates using new non-polynomial displacement fields via Carrera Unified Formulation. Compos. B Eng. 2016, 89, 127-142. [CrossRef]

13. Hong, C.C. Rapid heating-induced vibration of composite magnetostrictive shells. Mech. Adv. Mater. Struct. 2016, 32, 415-422. [CrossRef]

14. Hong, C.C. Rapid heating induced vibration of magnetostrictive functionally graded material plates. J. Vib. Acoust. 2012, 134, 021019. [CrossRef]

15. Ferreira, A.J.M.; Carrera, E.; Cinefra, M.; Viola, E.; Tornabene, F.; Fantuzzi, N.; Zenkour, A.M. Analysis of thick isotropic and cross-ply laminated plates by generalized differential quadrature method and a Unified Formulation. Compos. B Eng. 2014, 58, 544-552. [CrossRef]

16. Hong, C.C. Thermal vibration and transient response of magnetostrictive functionally graded material plates. Eur. J. Mech. A Solids 2014, 43, 78-88. [CrossRef]

17. Hong, C.C. Rapid heating induced vibration of circular cylindrical shells with magnetostrictive functionally graded material. Arch. Civ. Mech. Eng. 2014, 14, 710-720. [CrossRef]

18. Ajaj, R.M.; Beaverstock, C.S.; Friswell, M.I. Morphing aircraft: The need for a new design philosophy. Aerosp. Sci. Technol. 2016, 49, 154-166. [CrossRef]

19. Hu, W.; Yang, Z.; Gu, Y. Aeroelastic study for folding wing during the morphing process. J. Sound Vib. 2016, 365, 216-229. [CrossRef]

20. Huang, R.; Qiu, Z. Transient aeroelastic responses and flutter analysis of a variable-span wing during the morphing process. Chin. J. Aeronaut. 2013, 26, 1430-1438. [CrossRef]

21. Barbarino, S.; Bilgen, O.; Ajaj, R.M.; Friswell, M.I.; Inman, D.J. A review of morphing aircraft. J. Intell. Mater. Syst. Struct. 2011, 22, 823-877. [CrossRef]

22. Weisshaar, T.A. Morphing aircraft technology-New shapes for aircraft design. In Proceedings of the Multifunctional Structures/Integration of Sensor Antennas, Neuilly-sur-Seine, France, 1 October 2006; RTO-MP-AVT-141, Overview 1. pp. O1-1-O1-20.

23. Librescu, L.; Na, S.; Marzocca, P.; Chung, C.; Kwak, M.K. Active aeroelastic control of 2-D wing-flap systems operating in an incompressible flowfield and impacted by a blast pulse. J. Sound Vib. 2005, 283, 685-706. [CrossRef]

24. Chi, S.H.; Chung, Y.L. Mechanical behavior of functionally graded material plates under transverse load, Part I: Analysis. Int. J. Solids Struct. 2006, 43, 3657-3674. [CrossRef]

25. Qatu, M.S.; Sullivan, R.W.; Wang, W. Recent research advances on the dynamic analysis of composite shells: 2000-2009. Compos. Struct. 2010, 93, 14-31. [CrossRef]

26. Lee, S.J.; Reddy, J.N.; Rostam-Abadi, F. Nonlinear finite element analysis of laminated composite shells with actuating layers. Finite Elem. Anal. Des. 2006, 43, 1-21. [CrossRef]

27. Whitney, J.M. Structural Analysis of Laminated Anisotropic Plates; Technomic Publishing Company, Inc.: Lancaster, PA, USA, 1987.

28. Jafari, A.A.; Khalili, S.M.R.; Azarafza, R. Transient dynamic response of composite circular cylindrical shells under radial impulse load and axial compressive loads. Thin Walled Struct. 2005, 43, 1763-1786. [CrossRef]

29. Dowell, E.H.; Curtiss, H.C.; Scanlan, R.H.; Sisto, F. A Modern Course in Aeroelasticity; Sijthoff \& Noordhoff International Publishers B.V.: Alphen aan den Rijn, The Netherlands, 1978. 
30. Sepiani, H.A.; Rastgoo, A.; Ebrahimi, F.; Arani, A.G. Vibration and buckling analysis of two-layered functionally graded cylindrical shell considering the effects of transverse shear and rotary inertia. Mater. Des. 2010, 31, 1063-1069. [CrossRef]

31. Bert, C.W.; Jang, S.K.; Striz, A.G. Nonlinear bending analysis of orthotropic rectangular plates by the method of differential quadrature. Comput. Mech. 1989, 5, 217-226. [CrossRef]

32. Shu, C.; Du, H. Implementation of clamped and simply supported boundary conditions in the GDQ free vibration analyses of beams and plates. Int. J. Solids Struct. 1997, 34, 819-835. [CrossRef]

33. Hong, C.C. Varied effects of shear correction on thermal vibration of functionally graded material shells. Cogent Eng. 2014, 1, 938430. [CrossRef]

(C) 2017 by the author. Licensee MDPI, Basel, Switzerland. This article is an open access article distributed under the terms and conditions of the Creative Commons Attribution (CC BY) license (http:/ / creativecommons.org/licenses/by/4.0/). 